\title{
WITTGENSTEIN: UMA SOLUÇÃO FUNDACIONISTA AO PROBLEMA DO REGRESSO EPISTÊMICO
}

\author{
Eduardo Ferreira das Neves Filho \\ Juliano Santos do Carmo \\ Universidade Federal de Pelotas
}

\begin{abstract}
RESUMO: As notas que compõem a obra Da Certeza (Über Gewissheit) expressam nitidamente a preocupação de Ludwig Wittgenstein com os problemas clássicos da epistemologia, em especial o uso dos termos epistêmicos tradicionais e os erros costumeiros dos filósofos que negligenciam suas profundas estruturas gramaticais. Em diversas passagens é fácil observar a tentativa de esclarecer os erros de realistas, idealistas e céticos no que diz respeito às nossas alegações ordinárias de conhecimento em contextos céticos moderados. A questão do ceticismo sobre a justificação é um tema recorrente na epistemologia analítica contemporânea e, de certo modo, as soluções ofertadas a este problema ainda não são completamente adequadas. Existem muitas passagens de $\mathrm{Da}$ Certeza que possuem o potencial de lançar luz sobre questões fundamentais que encontram-se imbricadas neste debate, cuja discussão contemporânea tem sido fomentada pela instigante análise de Daniele Moyal-Sharrock (2005, 2007). O objetivo deste artigo é justamente tentar esboçar uma reposta wittgensteiniana ao problema do regresso epistêmico.
\end{abstract}

ABSTRACT: The notes that compose On Certainty (Über Gewissheit) clearly express the concern of Ludwig Wittgenstein with the classic problems of epistemology, in particular the use of traditional epistemic terms and the usual mistakes of philosophers who neglect their deep grammatical structures. In various passages is easy to observe the attempt to clarify errors of the realistic, idealistic and skeptical with regard to our common claims of knowledge in moderate skeptical contexts. The issue of skepticism about the justification is a recurring theme in Contemporary Analytical Epistemology and, in a sense, the solutions offered to this problem are not fully adequate. There are many passages in On Certainty that have the potential to shed light on fundamental questions that are intertwined in this debate, whose the contemporary discussion has been fostered by provocative analysis offered by Daniele Moyal-Sharrock $(2005,2007)$. This article is just trying to sketch a possible Wittgenstein's response to the epistemic regress problem. 


\section{Ceticismo: 0 Problema da Justificação Epistêmica}

O ceticismo sobre o conhecimento pode ser considerado a partir de uma dupla perspectiva ${ }^{1}$ : (1) o Ceticismo Epistêmico diz que não existe tal coisa como o conhecimento, uma vez que o mundo é considerado como incomensurável e indeterminável (contexto cético exigente), e (2) o Ceticismo sobre a Justificação diz que não existe crença verdadeira "adequadamente justificada" (contexto cético moderado). Em se tratando do Ceticismo sobre a Justificação, a maioria dos epistemólogos costuma assumir que o conhecimento implica necessariamente em crença verdadeira adequadamente justificada, ainda que não exista consenso a respeito do que pode contar como "justificação adequada"2. A estratégia habitual dos céticos consiste em tentar mostrar que as condições impostas às teorias da justificação (em especial o problema do Regresso Epistêmico) não são ou não podem ser satisfeitas.

O problema do Regresso Epistêmico remonta pelo menos a Pirro de Élis (365-270 a.C.), mas encontra muitos ecos em diversas posições filosóficas modernas e contemporâneas. Seja no caso das crenças que suportam outras crenças na cadeia inferencial de justificação, seja no caso das regras ou métodos aplicados no curso da justificação de uma crença, o problema do regresso epistêmico parece invalidar completamente as nossas alegações ordinárias de conhecimento. As teorias da justificação epistêmica que visam reabilitar nossas pretensas alegações de conhecimento podem ser divididas em "teorias fundacionais" e "teorias não-fundacionais", sendo que a diferença principal entre ambas as posições é justamente a resposta que oferecem à questão: "quais crenças e outros métodos inferenciais requerem justificação?”. As teorias não-fundacionais costumam defender que todas as crenças e métodos inferenciais requerem justificação. As teorias fundacionais, por outro lado, assumem que algumas crenças e métodos

\footnotetext{
${ }^{1}$ Ver: LUPER, S. The Skeptics: Contemporary Essays. Aldershot: Ashgate, 2003.

${ }^{2}$ Existem diversos outros problemas com a definição clássica de conhecimento, especialmente os contraexemplos de Gettier e o "Dilema de Sellars" que, embora sejam fundamentais para a discussão contemporânea sobre epistemologia, não serão tratados aqui. Ver: LUZ, A. Conhecimento e Justificação. Pelotas: Dissertatio-Filosofia, 2013. SARTORI, C. O Dilema de Sellars: Desafio ao Fundacionismo Epistêmico. Porto Alegre: Veritas, 2009.
} 
(crenças e métodos fundacionais) não necessitam de justificação, enquanto todas as demais crenças e métodos de justificação estão em última análise assentadas em crenças e métodos fundacionais ${ }^{3}$.

$\mathrm{Na}$ base do problema do Regresso Epistêmico, portanto, está a ideia de que para que uma crença seja adequadamente justificada ela precisa estar necessariamente vinculada a uma outra inferência ou a uma cadeia de inferências justificadas. $O$ cético sugere, neste caso, que não é possível encontrar um modo adequado de garantir este vínculo, pois (i) ou bem a cadeia inferencial deve começar com inferências que não estão baseadas em outras inferências; (ii) ou bem a cadeia inferencial não possui um início fundacional e admite processos circulares de justificação; (iii) ou bem a cadeia de justificação inferencial deve seguir infinitamente. Uma vez que cadeias infinitas de justificação inferencial são impossíveis para seres humanos finitos, pois sequer poderíamos compreendê-las, a última alternativa (iii) fica imediatamente excluída. Uma vez que cadeias circulares não geram a justificação adequada e que cadeias de justificação inferencial não podem começar com suposições arbitrárias, então ficam excluídas também as duas primeiras possibilidades. Não parece restar outra alternativa senão concordar com o cético sobre a justificação epistêmica acerca do fato de que não existem crenças adequadamente justificadas ou fundamentadas. As três condições expostas acima formam o famoso Trilema de Agripa ${ }^{4}$ :

(1) A justificação não pode regredir infinitamente (Problema do Regresso ao Infinito);

(2) A justificação não pode ser circular (Problema da Petição de Princípio)

(3) A justificação não pode estar baseada em meras suposições (Problema da Arbitrariedade);

A última condição às vezes é dividida em duas: (3) e

(4) A justificação não pode estar baseada em proposições disputáveis (Problema da Autoevidência) ${ }^{5}$.

\footnotetext{
${ }^{3}$ HARMAN. G. Skeptcism and Foundations. In. LUPER, S. The Skeptics: Contemporary Essays. Aldershot: Ashgate, 2003.

${ }^{4}$ LAÉRTIUS, D. Vidas e Doutrinas dos Filósofos Ilustres. Brasília: UNB, 2008. Livro IX.

${ }^{5}$ A formulação original encontra-se em: LUPER, S. Cartesian Skepticism. In: BERNECKER, S., PRITCHARD, D., Ed(s). The Routledge Companion to Epistemology. New York: Routledge, 2011, p. 415.
} 
De acordo com a posição cética, contudo, as teorias candidatas a resolver o Trilema de Agripa fracassam na exata medida em que não parece possível encontrar uma crença adequadamente justificada sem fracassar ao mesmo tempo em satisfazer conjuntamente as condições (1)-(4). Basta notar que se conhecimento é identificado com crença adequadamente justificada e se a justificação depende da satisfação das condições (1)-(4), então qualquer justificação finita (1) e não circular (2) deveria começar com uma premissa que não está baseada em qualquer outra afirmação, o que tornará essa premissa uma mera suposição (3). Além disso, se levarmos em conta a condição (4), torna-se realmente difícil encontrar uma noção adequada de justificação, pois qualquer proposição é em alguma medida disputável. Se uma "proposição disputável” for compreendida como uma "proposição bivalente", então as coisas se tornam um pouco mais complicadas, pois a justificação não poderia estar baseada em qualquer proposição, uma vez que a bivalência pode ser considerada como uma característica básica de qualquer proposição genuína.

As principais estratégias disponíveis para tentar resolver o Trilema de Agripa são as seguintes:

(a) Mostrar que o conhecimento não requer justificação ${ }^{6}$ a partir da suposição de que nossas crenças sobre o mundo são produzidas através de um método confiável (Confiabilismo, Externalismo, Naturalismo e demais teorias nãofundacionais), mesmo que não estejamos justificados em pensar que elas tenham sido obtidas dessa forma ${ }^{7}$.

(b) Recusar a condição (3), demonstrando que algumas crenças podem ser justificadas de um modo não-inferencial (ou ainda, não justificadas por outras crenças). Neste caso, seria preciso mostrar que as crenças justificadas de modo não-inferencial não implicam em deixar de satisfazer a condição (1).

(c) Negar que a justificação adequada de uma crença deva satisfazer especialmente a condição (2), e procurar defender a legitimidade da justificação circular.

(d) Rejeitar a quarta condição (4), pois ela supostamente inviabiliza qualquer

\footnotetext{
6 Ver: LUPER, S. The Causal Indicator Analysis of Knowledge. Philosophy and Phenomenological Research 47: 563-89. DRETSKE, F. Skepticism: What Perception Teaches. In: LUPER, S. The Skeptics. Aldershot: Ashgate Publishing, 2003, pp. 105-19; DRETSKE, Fred. Knowledge and the Flow of Information. MIT Press, 1982.

${ }^{7}$ Ver: MILLIKAN, R. White Queen Psychology and Other Essays for Alice. MIT Press, 1993;
} 
reivindicação de conhecimento, já que seria aparentemente um absurdo pensar que não temos justificação ao crer em proposições que outros contestam.

(e) Procurar satisfazer as quatro condições e mostrar o que há de errado nas considerações habituais do ceticismo sobre a justificação.

Em Da Certeza, Wittgenstein procurou mostrar que certas proposições que superficialmente parecem proposições empíricas são, pelo contrário, proposições lógicas ou gramaticais ${ }^{8}$. Certas proposições mooreanas 9 do tipo "Eis aqui uma mão", parecem dizer algo factual sobre o mundo e por isso poderiam erroneamente ser consideradas como estando sujeitas à dúvida e aos habituais recursos de verificação aplicados às proposições empíricas. As proposições gramaticais estão logicamente imunes à dúvida e servem como o próprio fundamento a partir do qual as proposições empíricas adquirem sentido. Ao que tudo indica, Wittgenstein não estava tão interessado em refutar as dúvidas céticas a respeito da existência de um mundo externo (ceticismo global), mas, antes, seu interesse estava voltado prioritariamente para o uso dos termos epistêmicos (tais como a utilização de verbos tais como "saber" e auto-atribuições de crença do tipo "eu sei").

Temos razões para crer que a obra Da Certeza tem o potencial de lançar luz sobre uma série de questões pertinentes ao Trilema de Agripa na epistemologia contemporânea (sobretudo no que se refere ao problema do Regresso Epistêmico), pois além de fomentar a ideia de que conhecimento e certeza pertencem a categorias distintas (satisfazendo a condição (2)), Wittgenstein defende que "certezas" são os próprios fundamentos de todo o nosso sistema conceitual (satisfazendo as condições (1) e (3)) e que "certezas" não são proposições (satisfazendo a condição (4)). Seguindo os insights de Daniele Moyal-Sharrock sobre a obra Da Certeza, vamos esboçar agora uma possível solução wittgensteiniana de cunho fundacionista ao problema do Regresso Epistêmico.

\footnotetext{
${ }^{8}$ Ver: MCGUINN, M. Responding to the Sceptic: Therapeutic versus Theoretical Diagnosis. In: LUPER, S. The Skeptics: Contemporary Essays. Aldershot: Ashgate, 2003.

${ }^{9}$ Ver: CHILD, W. Wittgenstein: uma introdução. Porto Alegre: Artmed, 2013.
} 


\section{Wittgenstein: Certeza Objetiva e Conhecimento}

É reconhecido por boa parte dos comentadores de Wittgenstein que as anotações que produziu em seus dois últimos anos de vida têm grande importância para a epistemologia, particularmente no debate com o ceticismo em suas versões mais radicais e abrangentes. A tarefa de organizar e interpretar os seiscentos e setenta e seis parágrafos, reunidos sob o título Da Certeza (OC), foi desenvolvida por G.E.M. Anscombe e G.H. Von Wright, está em edição bilíngue (alemão/inglês), e cujas traduções alcançam diversos idiomas. As recalcitrantes observações de Wittgenstein em OC têm provocado as mais variadas polêmicas quando se trata de compreender possíveis consequências da análise sobre os conceitos de conhecimento e certeza, mas também sobre o desenvolvimento de sua própria filosofia ${ }^{10}$.

Ponto pacífico na fortuna crítica é atribuir o ensejo de Wittgenstein, ao produzir as referidas anotações, a seu interesse pela defesa que G. E. Moore tentou proporcionar ao senso comum, cujos resultados foram publicados por este último em dois artigos no início do século XX: Prova de um mundo exterior (MOORE, 1939) e Uma defesa do senso comum (MOORE, 1925). Na 'prova' da existência de um mundo exterior, Moore pretende derivar que 'há objetos exteriores' da premissa de que 'existem duas mãos humanas', e esta do fato de levantar cada uma de suas mãos à audiência, durante famosa conferência, dizendo duas vezes 'eis aqui uma mão'. Ora, segundo Wittgenstein, o 'erro' na 'prova' não seria decorrente do mau uso da lógica, já que realmente se pode inferir a conclusão das premissas sem dificuldade, mas de sua irrelevância filosófica, visto que as premissas não seriam mais certas do que a conclusão (CHILD, 2013, 201). Ainda, se o objetivo de Moore com a 'prova' era refutar idealistas e céticos, Wittgenstein vai lembrar a Moore que ainda lhe faltaria, para atingir esse fim, realizar "um diagnóstico de exatamente onde e como o

\footnotetext{
${ }^{10}$ Por exemplo, D. MOYAL-SHARROCK (2007) defende que o Da Certeza seria o marco divisor de águas para uma 'terceira' fase do pensamento de Wittgenstein, ou, como sustenta, inaugura no pensamento do autor um Pragmatismo Lógico, ou um 'Terceiro' Wittgenstein. Para maiores informações, veja Moyal-Sharrock, 2007. Já CHILD (2013) sustenta que nas Investigações Filosóficas já há indícios de temas semelhantes, sobretudo nos parágrafos 324-6 e 466-486.
} 
idealista e o cético se enganam” (CHILD, 2013, 202). Moore não cumpre a tarefa trivializando a argumentação e permanecendo na vala comum em que os oponentes (céticos e idealistas) pretenderiam que ele permanecesse: não prova nem que realmente existe um mundo exterior independente de nós, tampouco que, se realmente este mundo existe, que possamos conhecê-lo, por razões óbvias.

O erro de Moore ao asserir que "Sei com certeza (grifos nossos) que tenho duas mãos”, se pode sustentar, está em atribuir à certeza um papel subjetivo, que indica, como Wittgenstein diversas vezes chama a atenção em OC, apenas uma espécie de 'convicção inabalável'. O ponto é que a conviç̧ão de Moore não poderia, como tal, ser dada como garantia de conhecimento, mas apenas indicaria uma simples atitude de crença. Quando se levanta sobre uma crença uma pretensão de conhecimento devem-se dar razões, de modo a 'demonstrar' a alguém que de fato estamos de posse de algo forte como 'conhecimento':

\footnotetext{
Se diz 'Sei ...' quando se está em condições de dar razões apropriadas. 'Sei...' está vinculado a uma possibilidade de demonstrar a verdade. Se alguém sabe algo - sempre que esteja convencido - pode manifestar isso. Mas se o que acredita é de tal tipo que as razões que possa dar não são mais seguras que sua asserção, não pode dizer que sabe o que acredita (OC 243).
}

Moore teria, então, de responder como sabe que há objetos exteriores, do mesmo modo que responder como sabe que tem duas mãos, premissa usada por ele para derivar a conclusão de que há objetos exteriores. Para isso, seria insuficiente levantar suas mãos à audiência. As 'razões apropriadas' para uma alegação de saber, de que fala Wittgenstein, falham, no caso, tanto para a premissa, quanto para a conclusão da derivação na 'prova' de Moore, pois no uso correto da expressão 'Eu sei ...', somos capazes de oferecer "os fundamentos deste saber, ou pelo menos, eles podem ser dados” (OC 484). É importante observar que em contextos em que conhecimento é alegado "(i) há uma possibilidade lógica de erro ou ignorância, e (ii) tal possibilidade tenha sido afastada por meio de 'regras evidenciais claras'” (GLOCK, 1998, p. 74).

$\mathrm{Na}$ ausência de condições adequadas para uma alegação de conhecimento, pois, amplia-se o erro de Moore: ele afirma 'saber com 
certeza' que tem duas mãos. Ora, se não é adequado o uso da palavra 'saber' do modo como o fez Moore (como aponta Wittgenstein), não é adequado qualificar esse 'saber' com um caso de 'certeza', que é considerada, ao menos em parte da tradicional teoria do conhecimento, como o mais alto grau da justificação epistêmica. Ao contrário, 'certeza', do modo como Moore utiliza a expressão, apenas indica uma certeza subjetiva, uma forte convicção, e nada mais, além disso. A certeza de Moore, no máximo, ganha ares 'metafísicos', ideia recusada por Wittgenstein em vários parágrafos de $\mathrm{OC}^{11}$.

Até aqui a análise se desenvolve de um ponto de vista negativo. No entanto, embora Wittgenstein rejeite que Moore possa 'saber com certeza' que possui duas mãos, 'Tenho duas mãos' e 'Há objetos exteriores' e diversos outros truísmos semelhantes em função, admite, fazem parte de uma classe de certezas objetivas, que pertencem a uma categoria diversa da categoria do conhecimento (MOYAL-SHARROCK, 2005, p. 77), possuindo determinado (e importante) papel em nossos jogos de linguagem:

Com a palavra 'certo' expressamos a convicção absoluta, a ausência de qualquer tipo de dúvida, e tratamos de convencer aos demais. Isso é certeza subjetiva. Mas quando uma coisa é objetivamente certa? - Quando o erro não é possível. Mas que tipo de possibilidade é esta? O erro não tem que ficar excluído logicamente? (OC 194)

Wittgenstein menciona as certezas objetivas em OC de diferentes maneiras, no entanto, parece haver uma confluência de significados nas expressões que são utilizadas para caracteriza-las: por exemplo, elas aparecem como 'imagem de mundo' (OC 94), isto é, seriam 'proposições'12 que compõem nossa imagem de mundo, possuindo um

\footnotetext{
${ }^{11}$ De Acordo com Glock (2008, p. 74), “a expressão 'Eu sei ...' não pode tolerar, no entanto, uma 'ênfase metafísica' dessa natureza (OC 21, 251, 425, 481-2, 533-4)" - a saber, no uso atribuído por Moore.

${ }^{12}$ Utilizamos o termo 'proposição' destacado nessa passagem, visto que elucida o modo standard de apresentação do pano de fundo das certezas objetivas em OC. Entretanto, adiante sustentaremos que, na verdade, as certezas objetivas não se caracterizam como proposições, e são melhor compreendidas como crenças básicas.
} 
'papel lógico determinado' (OC 136), como o que diz respeito às nossas 'crenças mais básicas' (OC 253), servindo como uma espécie de 'fundamento' aos nossos jogos de linguagem (OC 401-2), como aquilo que 'está firme' (OC 655).

Esses 'adjetivos', que qualificam as certezas objetivas, fazem alusão a característica de estarem imunes à dúvida. Como todo o jogo de linguagem, o jogo de linguagem do duvidar possui suas regras. Não faz sentido duvidar das regras, dos próprios fundamentos dos nossos jogos de linguagem, daquilo que nos ajuda a compor nossa imagem de mundo, do quadro de referência sobre o qual erigimos nossas crenças:

'Desta proposição não posso duvidar sem renunciar a todo o juízo'. Mas, que tipo de proposição é esta? Isso lembra o que Frege disse sobre a identidade. Evidentemente, não se trata de uma proposição empírica. Não pertence à psicologia. Tem, melhor, o caráter de uma regra (OC 494).

(...) É dizer, nos interessa, para que o juízo seja possível, que não possa haver dúvida alguma com respeito a certas proposições empíricas. Ou também: tendo a crer que nem tudo que tem a forma de uma proposição empírica é uma proposição empírica (OC 308).

Wittgenstein afirma que não podemos duvidar dos fundamentos (ou regras) de nossos jogos de linguagem, pois dúvidas sobre eles paralisariam os jogos de linguagem. Essas 'regras' são certas, pois constituem a 'base' sob a qual erigimos nossos jogos de linguagem, e quaisquer dúvidas legítimas só poderão ser levantadas quando as tivermos sob nossa 'imagem de mundo': "Quem quer duvidar de tudo, nem sequer chegaria a duvidar. $\mathrm{O}$ mesmo jogo da dúvida pressupõe a certeza" (OC 115).

Aqui temos uma 'pista' para tentar argumentar sobre a possibilidade de um fundacionismo em OC, e tentar mostrar como haveria, nesta perspectiva, uma solução ao problema do regresso epistêmico. A investigação, aqui, passa pela compreensão de MoyalSharrock $(2005,2007,2013,2014)$ tem das certezas objetivas como crenças básicas, o que passamos a expor a seguir. 


\subsection{Certezas Objetivas como Crenças Básicas que ocorrem em ação}

No parágrafo 204 de OC, Wittgenstein faz uma importante afirmação:

No entanto, a fundamentação, a justificação da evidência tem um fim; - mas o fim não está em que certas proposições nos pareçam verdadeiras de forma imediata, como se fosse uma espécie de ver de nossa parte; pelo contrário, é nossa ação que jaz no fundo do jogo de linguagem (OC 204).

Essa passagem sugere, de acordo com Moyal-Sharrock, que Wittgenstein está traçando um limite 'lógico', e não sustentado graus, entre certeza objetiva e conhecimento. Conhecimento está, obviamente, baseado em graus. Certezas objetivas não. O 'erro não é possível', no caso das certezas objetivas, pois não se trata de acrescentar razões à crença: "a certeza que Wittgenstein está procurando definir como objetiva, é objetiva não meramente oposta à subjetiva, mas assim: ela não está baseada de modo algum em graus. Pois, quando razões são apresentadas, estamos no domínio do conhecimento" (MOYALSHARROCK, 2005, p. 77). Por seu turno, as certezas objetivas são mencionadas por Wittgenstein como não-fundadas, não-epistêmicas, e desempenham um papel lógico importante na 'armação de nossos pensamentos'.

Decorre que os modos utilizados por Wittgenstein para destacar a certeza objetiva fazem com que, de acordo com MoyalSharrock (2005, p. 78), aparentemente Wittgenstein pareça sustentar inconsistências. A primeira delas: certeza objetiva é tomada tanto como regra da gramática, como quanto modo de ação (o que o parágrafo 204, citado logo acima, pode sugerir). Essa inconsistência é dissipada, segundo a autora, quando Wittgenstein acaba considerando, mesmo que isso não apareça de modo claro o bastante em OC, 'certeza objetiva' e 'certezas objetivas'; no primeiro caso, Wittgenstein identifica o aspecto fundacional da certeza objetiva, e, quando fala de certezas objetivas, os objetos dessa certeza, isto é, as hinges (dobradiças), tais como 'Aqui há uma mão', 'Nosso cérebro não está oco', 'A Terra existe há mais de cinco minutos', etc.

Ao se tentar explicar certeza objetiva tomada em seu sentido 
fundacional aparentemente surge outra inconsistência. Isto é, dois 'ângulos' filosóficos parecem ser oferecidos na análise de Wittgenstein: um fenomenológico e o outro categorial. A aparente inconsistência é fruto apenas das imagens utilizadas para informa-los, mas, na verdade, eles são complementares (MOYAL-SHARROCK, 2005, p. 79).

Como categoria doxástica (MOYAL-SHARROCK, 2005, pp. 789), certeza objetiva tem caráter fundacional, seria a rocha dura das nossas convicções, aquela em que se apoia todo o nosso sistema de crenças, o que nos permite distinguir o verdadeiro do falso (OC 94), compondo uma imagem de mundo (OC 162), assegurando normas de descrição (OC 167), sob as quais não se pode supor corretamente, visto que a suposição, nesse caso, dar-se-ia sobre o próprio fundamento de nossas ações (OC 411). A consequência de todos estes apontamentos nos sugere que o papel da certeza objetiva é o de regra da gramática:

Se concebermos 'Eu sei, etc.' como uma proposição gramatical, é óbvio que o 'Eu' não pode ser importante. O que, no fundo, quer dizer: 'Não há, neste caso, nada como uma dúvida', ou 'A expressão 'Não sei' carece de sentido aqui'. Por suposto, disso se segue que 'Eu sei' tampouco tem sentido (OC 58).

Por seu turno, como atitude doxástica, a análise é tomada, para MoyalSharrock, em um sentido fenomenológico, e atitude deve ser compreendida, nesse caso, tanto como disposição, quanto de ocorrência propriamente dita. Quer dizer, se está falando de nossas 'certezas objetivas' (no plural mesmo), aquilo que se mostra no que dizemos e fazemos. Mas em que relação a que se orientam nossas falas e ações? Moyal-Sharrock observa que este tipo de atitude doxástica, ao contrário daquilo que se poderia supor, não é direcionado a crenças que, mas orienta-se em relação a 'objetos' que fazem parte da gramática, tais como estados de coisas, indivíduos, etc., que pertencem a gramática, "objetos que são usados como paradigmas de nossos métodos de descrição (...). Tais objetos (estados de coisas, indivíduos, etc.) são, assim como amostras ou objetos usados em definições ostensivas, parte da gramática” (MOYAL-SHARROCK, 2005, p. 81). Como tais, não são apreendidos em palavras, mas constituem nossas crenças mais básicas, mostram-se em nossas atitudes, são know-how, e pertencem à gramática. 
A criança aprende a acreditar em muitas coisas. Isso é, aprende, por exemplo, a agir de acordo com essas crenças pouco a pouco, se forma um sistema com as coisas que acredita e, em tal sistema, alguns elementos se mantêm imutáveis e firmes, enquanto outros são mais ou menos móveis. O que se mantém firme o faz não por que seja óbvio intrinsecamente ou convincente, senão porque se sustenta naquilo que o rodeia (OC 144).

Certezas objetivas formam uma estrutura, uma fundação. Em OC 96, Wittgenstein nos pede para imaginar que 'proposições', "que tem a forma de proposições empíricas”, e que funcionariam como os canais por onde fluem as proposições empíricas. Esse seria o "fundo me minhas convicções" (OC 248). Justamente aí se encontra o fim das razões ${ }^{13}$, o fundamento das crenças, ou seja, as crenças sem fundamentos (OC 251), o lugar em que a dúvida não faz sentido. Essa seria a rocha dura ${ }^{14}$ das nossas certezas, "constituem um sistema, um edifício” (OC 102). Moyal-Sharrock chama a atenção ao fato de que é esse um 'conjunto' que funciona com todas as nossas crenças básicas, e não cada uma delas isoladamente (OC 141); cada uma dessas crenças será fruto de aprendizado e experiências (OC 279).

Mas vejamos. Estamos falando de crenças, porém, crenças que não possuem um conteúdo proposicional ${ }^{15}$. Por que chamar a esse

\footnotetext{
${ }^{13} \mathrm{E}$, portanto, como ainda frisaremos, uma resposta ao problema do regresso epistêmico.

14 Aqui, também, tomada a obra de Wittgenstein como uma continuidade, posição que sustentamos, a rocha dura das nossas convicções de que Wittgenstein trata em OC seria uma apresentação não-enigmática da menção à rocha dura nas Investigações Filosóficas. Esse ponto, no entanto, não é tema de discussão aqui.

${ }^{15}$ Moyal-Sharrock sustenta que o uso 'especializado' do termo proposição, em Wittgenstein, se mantém desde a perspectiva tractariana, e coloca, como condição à proposicionalidade, a bipolaridade. De acordo com a autora, boa parte da fortuna crítica corrobora essa posição, garantindo que há evidências para isso em todos os textos de Wittgenstein, particularmente no Da Certeza (OC 320-1); ou seja, o conteúdo de uma proposição é compreendido "como uma entidade abstrata à la Frege; como o 'pensamento' de Frege, o sentido de uma sentença" (MOYAL-SHARROCK, 2007, p. 34). As proposições empíricas, por isso, estariam sujeitas à bipolaridade. Ora, as certezas objetivas, apesar de aparentarem serem proposições empíricas, não estão sujeitas ao critério da bipolaridade, tendo antes a função de regras da gramática. Assim sendo, seriam casos degenerados de proposição, ou não seriam genuínas proposições; uma regra não é verdadeira, nem falsa, tampouco uma regra é candidata à dúvida, verificação ou falsificação. Assim, aquilo que se costumou chamar de 'proposições-dobradiças' (hinge propositions) seria, antes de qualquer coisa, apenas um modo heurístico de nos reportarmos às regras da gramática, que se mostram em ação.
} 
'fenômeno' de crença? Em primeiro lugar, pois "crença não demanda justificação, não implica que uma inferência tenha sido feita” (MOYALSHARROCK, 2007, p.24), e desse modo prescinde das demandas para uma alegação de conhecimento, como vimos acima. Em segundo lugar, pois parece um termo apropriado para destacar uma 'manifestação imediata', uma 'segurança' (OC 510), algo que não é nem justificado, nem injustificado, mas 'algo animal' (OC 359). Essa 'confiança', segundo a autora, desperta uma espécie de 'fé cega' (certeza implica, pois, a completa ausência de dúvida), nos fazemos valer de todo o nosso background, e expressamos essas crenças mais básicas não em palavras, mas em ação, elas se expressam não em um saber-que, mas em know-how.

Quando falamos de background, não nos referimos a um conjunto de observações teóricas sobre o mundo, mas ao nosso arcabouço de práticas, sobre os quais nenhuma atitude 'consciente' deve se fazer necessária quando agimos, quando não desenvolvemos nenhuma resistência a isso (a ausência de reflexão, aqui, é uma característica importante, pois não há 'atenção' presente nas ações, quando se trata de agir; ao contrário, a atenção não é associada a uma crença básica $\left.{ }^{16}\right)$. Por exemplo, ao acordamos pela manhã, não checaremos diariamente se há, ou não, um precipício ao lado de nossa cama, de modo que venhamos a cair ao nos levantarmos. Tampouco nos certificaremos se nossa escova de dente realmente é sólida, se todos os dias nós teremos dentes para escovar, etc. São justamente esses 'pontos de contato' com nossas crenças básicas, certezas objetivas, que fazem do know-how 'objetivo' para nós (MOYAL-SHARROCK, 2005, p. 87), seja construindo nossa imagem de mundo, seja compondo o quadro de referência sobre o qual erigimos nossas crenças:

\footnotetext{
a fundação de todas as nossas ações (OC 414) (incluindo, é claro, nossos jogos de linguagem (OC 403, 411)) é (...) descrita em termos do agir. (...) Com isso, Wittgenstein quer dizer que nossa certeza fundacional é uma certeza prática (não é teorética, nem proposicional, nem uma certeza advinda de uma pressuposição) que se manifesta como modo de ação (OC 7, 284-5, 395) (...) (MOYAL-SHARROCK, 2005, p. 89).
}

\footnotetext{
${ }^{16}$ Obviamente, a reflexão sobre o que se passa no caso das certezas objetivas é resultado na análise filosófica, não há incoerência aqui.
} 
Em sua perspectiva fenomenológica, as certezas objetivas ocorrem em ação, isto é, nessa leitura, uma certeza objetiva, uma hinge (dobradiça), não pode ser dita, ela se mostra em ação (MOYALSHARROCK, 2005, p. 89); a assunção mais adequada para caracterizar os seus papéis, como hinges, é apresenta-las como regras de gramática, como vimos, e sublinhar que tais regras se mostram no fluxo dos nossos jogos de linguagem.

Há casos, contudo, em que algumas 'proposições', que têm a forma de hinges, poderão ser faladas ${ }^{17} \mathrm{em}$ nossos jogos de linguagem. Nessas 'circunstâncias', não funcionam como hinges, mas apenas como proposições empíricas. O termo empregado por Moyal-Sharrock para destacá-las é doppelgänger, uma espécie de representação idêntica de uma hinge, mas com função de proposição empírica propriamente dita.

Por exemplo: suponha-se que a administração central de um campus universitário quer garantir que todas as pessoas com necessidades especiais possam ser atendidas com qualidade em todos os prédios dos diferentes campi. Então, uma checagem é realizada junto à comunidade universitária, mediante um conjunto de perguntas. Entre elas, pergunta-se, por telefone ou por e-mail, quantas mãos, etc., tem a pessoa, e a resposta poderia ser "Eu tenho duas mãos". Nesse caso, a função da 'resposta' é de proposição empírica. Em outros casos podemos proferir (falar) certas doppelgänger com o propósito de esclarecer o uso de regras, como o fazemos com crianças, por exemplo. Isso não quer dizer que hinges, como hinges, possam ser ditas com propósitos descritivos (OC 548) ${ }^{18}$ - como tentou fazer Moore em sua 'prova':

Uma regra gramatical não pode ser dita; ela apenas se mostra no que dizemos e fazemos [o que mostraria o errro no caso da 'prova' de Moore - acréscimo nosso]. Quando escreve que algo não pode ser dito, Wittgenstein quer dizer que isso não pode

\footnotetext{
${ }^{17}$ Moyal-Sharrock mantém que a distinção tractariana entre dizer/mostrar também vale para OC. Desse modo, algumas 'proposições', embora não possam ser ditas, podem ser faladas. Para a autora, é possível dizer que Wittgenstein endossaria essa distinção: nem tudo o que é falado, é dito; por exemplo, uma 'regra' pode ser falada, mas não dita. Confira em Moyal-Sharrock (2007, pp. 43-7).

${ }_{18}^{18}$ Isso significa dizer que hinges são inefáveis de um ponto de vista 'lógico' e 'prático'.
} 
ser parte corrente em um jogo de linguagem; não que isso não possa ser proferido com propósitos heurísticos (MOYALSHARROCK, 2005, p. 91).

Por seu turno, é importante notar que um proferimento de uma hinge pode ser realizado na análise filosófica, e tem, nesse caso, um propósito bem delimitado, tem função de esclarecimento, uma função heurística: "me sento junto a um filósofo no jardim; ele diz repetidamente 'Sei que isso é uma árvore' enquanto aponta para uma árvore junto a nós. Uma terceira pessoa se aproxima e o escuta, e eu digo a ela: 'Este homem não está louco: apenas filosofamos" (OC 467).

Moyal-Sharrock pede atenção para a formulação/articulação das hinges, por um lado, e sua ocorrência ou manifestação, por outro. Neste último caso, uma hinge deve ser compreendida, como já vimos, como uma certeza animal, como não-proposicional, como uma espécie de confiança animal em certas coisas, e que se mostra em nossa ação, o que podemos chamar de uma descrição fenomenológica da função da hinge.

No entanto, como a leitura do parágrafo (OC 467) nos sugere, a elucidação da 'função' das hinges faz com que (ao exemplificarmos sua função 'mencionando' algumas delas) possamos pensar que elas possuem algum conteúdo, e que, portanto, ocupariam o 'lugar' de proposições, sendo estas o 'conteúdo' de nossas crenças. Aqui reside o erro. A formulação de uma hinge terá, apenas, a função de elucidar seu papel no jogo de linguagem, por meio de uma descrição categorial (por meio de exemplos, de certezas objetivas): "isso tenta elucidar o status dessas certezas promulgadas (enacted) - nossos modos ordinários de agir - em nosso sistema de crenças” (MOYAL-SHARROCK, 2005, p. 93).

\subsection{Crenças básicas como fundação e como solução ao problema do regresso}

$\mathrm{Na}$ última seção desse artigo, gostaríamos de esclarecer duas questões. Em primeiro lugar, visto que a assunção de que nossas certezas objetivas, nossas crenças básicas, constitui uma espécie de 'fundação', tentar dar uma resposta ao problema do regresso epistêmico. 
Em segundo lugar, mostrar como seria possível que crenças básicas, ainda que não tenham o papel de 'princípios', possam, ainda assim, garantir as nossas demais crenças, ou seja, realmente poder-se falar de uma 'fundação', apesar de a relação entre crenças básicas e crenças nãobásicas não seja construída mediante processos inferenciais.

Quanto a uma resposta ao problema do regresso epistêmico, a partir da leitura wittgensteiniana de OC proporcionada por MoyalSharrock podemos afirmar que se pode cumprir as quatro condições elencadas no princípio deste artigo, a saber: a) que a justificação de nossas crenças não se siga de um argumento circular, b) que a solução não se baseie em suposições, c) que não se caia em um regresso infinito de razões e d) que a justificação não esteja baseada em proposições disputáveis.

Em relação à primeira condição, observe-se que não há circularidade na argumentação, visto que nossas crenças básicas compõem a 'rocha dura' de nossas crenças, a imagem de mundo sobre a qual construímos nossas convicções e nossas crenças justificadas em geral (as certezas são os fundamentos de todo o nosso sistema conceitual). Para que funcionem nossos jogos de linguagem, o próprio jogo de linguagem do duvidar necessitará de regras apropriadas, isto é, não se pode duvidar daquilo que é fundamento de nossas crenças, visto que "dúvidas sempre se baseiam em razões" (GLOCK, 1998, p. 74):

\footnotetext{
'Sei que sou um homem'. Para nos darmos conta de quão pouco claro é o sentido desta proposição, consideremos sua negação. Quanto muito, poderíamos interpretá-la assim: 'Sei que tenho os órgãos próprios de um ser humano". (Por exemplo, um cérebro que, de todos os modos, nunca ninguém viu). Mas, que acontece com uma proposição do tipo 'Sei que tenho um cérebro'? Posso colocá-la em dúvida? Faltam-me razões para a dúvida! Todo conta a seu favor, nada contra ela. No entanto, é possível imaginar que por meio de uma operação se comprovasse que meu crânio está vazio (OC 4).
}

Por seu turno, nossas crenças básicas não são 'suposições', o que responde a segunda condição, elas não são nenhum tipo de construto intelectual destinado a cessar, de modo artificial, uma cadeia de razões. Nossas crenças básicas, nossas certezas objetivas, não são 'intelectuais', mas estão presentes em nossa vida cotidiana como know-how, são mais 
bem compreendidas como as regras que orientam nossa participação nos jogos de linguagem, compõem a rocha dura das nossas convicções, como vimos, e ocorrem em ação. Desse modo, a terceira condição, a saber, que se apresente um modo de evitar o regresso infinito de razões, também é cumprida:

O que os filósofos têm chamado de 'crenças básicas ou tácitas' não podem, às custas do regresso infinito, serem elas mesmas crenças proposicionais, e a concepção wittgensteiniana de certeza dobradiça mostra que elas não são. Enquanto epistemólogos tem sempre pensado em nossas crenças básicas como proposições, Wittgenstein as vê como regras da gramática ou limites de sentido que se manifestam como modos de ação (MOYAL-SHARROCK, 2013, p. 6)

A quarta condição pode ser respondida de modo evidente. A 'fundação' oferecida por Wittgenstein é construída sobre certezas promulgadas (enacted), e não está baseada em proposições disputáveis; o ponto de partida de Wittgenstein não se dá sobre proposições, nem está aberto ao domínio do que pode ser verdadeiro ou falso; a 'base' ou a 'fundação' está em ação, manifesta-se como know-how, e é alcançada 'diretamente'.

Mas aqui surge um problema. Se for possível sustentar que a base ou fundação ao conhecimento é composta por nossas crenças básicas, elas deveriam servir de sustentação para nossas crenças não básicas, o que particularmente é negado por Wittgenstein: "a partir das proposições fulcrais [como Glock as denomina, acréscimo nosso] não deduzimos outras verdades; calcamo-nos nelas como um 'pano de fundo' para nossa argumentação racional” (GLOCK, 1998, p. 77).

Essa questão surge como fio condutor da investigação de D. Pritchard (2012) em seu artigo Wittgenstein and the groundlessness of our believing. Ele observa que Wittgenstein pretende assegurar que as crenças básicas possuam duas características importantes: ser imunes à dúvida e ao suporte racional, no que em nada diverge do que foi apresentado aqui até agora. Por sua vez, toda a avaliação racional é sempre local, e sempre pressuporá as hinges (dobradiças), que são nãoracionais. A consequência do argumento, para o autor, é que Wittgenstein apresenta certa concepção das 'estruturas racionais', cuja 'base' é sempre composta pelas dobradiças que são imunes à avaliação racional, visto que identificam um tipo confiança 'primitiva' (OC 475), 
evitando o regresso de razões. O ponto de divergência entre Pritchard e Moyal-Sharrock irá concentrar-se, contudo, justamente sobre a nãoproposicionalidade das hinges, e das consequências que uma posição como essa poderá trazer à epistemologia.

Pritchard adverte que se segue um problema fundamental para a análise de Wittgenstein, se as coisas são colocadas dessa maneira: não é justamente isso que o cético quer que assumamos, que a base para nossas crenças seja não-racional? Assim colocada a questão, a pretensa rejeição ao ceticismo ficaria comprometida: para Wittgenstein, o cético serraria o galho em que está sentado, visto que não se pode duvidar dos próprios fundamentos que permitem com o que o jogo do duvidar seja praticado. Mas, se isso é assim, então deveríamos ser capazes de mostrar como nossas crenças básicas 'suportam, realmente, a casa toda'; como, em cenários locais, nosso suporte racional não estaria definitivamente marcado pela 'ausência de um suporte racional' (se Wittgenstein está certo! - visto que uma cadeia de razões, para Wittgenstein, sempre tem um fim, e, se está correta a leitura apresentada até agora em nosso artigo, o fim é a ação).

Uma segunda questão a responder, segundo Pritchard (2012, p.5), que é decorrente da primeira, é que parece possível, em alguns casos, que determinados raciocínios nos permitam acreditar, com razões, em alguma hinge, o que Wittgenstein não aceitaria, visto que, para ele, não seria possível dar razões às hinges. $O$ raciocínio a que se reporta Pritchard é construído mediante o recurso do Princípio de Fechamento:

Se $\mathrm{S}$ sabe que $\mathrm{P}$ e $\mathrm{S}$ competentemente deduz $\mathrm{Q}$ de $\mathrm{P}$, assim formando sua crença de que $\mathrm{Q}$ sobre a base de sua competente dedução, enquanto mantém seu conhecimento de que $\mathrm{P}$, então S sabe que Q(PRITCHARD, 2012, p. 7).

Em um exemplo: Se $S$ sabe que $P$, 'Napoleão venceu a batalha de Austerlitz em 1805 e disso deduz competentemente que Q, 'O universo não pode ter vindo a existir a cinco minutos atrás', então, então teria base para saber que $Q$, uma hinge. Disso se segue que seria possível adquirir suporte racional para uma hinge, o que não se encaixaria na visão wittgensteiniana em OC, usualmente defendida. Para Pritchard, aqui teríamos um dilema: ou negamos um princípio aparentemente plausível, o Princípio do Fechamento, ou negamos que crenças não- 
básicas como $\mathrm{P}$ tenham algum suporte racional. Essa última implica que o ceticismo não seria rejeitado nos cenários 'locais' pretendidos por Wittgenstein ${ }^{19}$.

A objeção de Pritchard é inadequada e recebeu resposta de Moyal-Sharrock. Mas, se por um lado nos parece uma leitura equivocada, por outro nos proporcionará acrescentar uma possível (e importante) consequência ao debate. Primeiramente, deixem-nos reconstruir a estrutura da argumentação de Pritchard ao colocar o problema exposto acima:

\section{Esquema Pritchard}

1. Alguém possui sustentação para saber que $\mathrm{P}$, 'Napoleão venceu a batalha de Austerlitz em 1805';

2. Uma hinge (dobradiça) relevante no cenário previsto em 1 seria Q: 'A Terra existe há mais tempo do que cinco minutos';

3. Q não pode ser, como é uma hinge, racionalmente sustentada;

4. $Q$ não pode ser racionalmente sustentada, pois é fundamental (em conjunção com outras hinges, em um cenário local) para a negação de um cenário cético radical;

5. Qualquer pessoa racional (S), razoavelmente reflexiva, é capaz de reconhecer que saber que $\mathrm{P}$ implica na rejeição da hipótese cética-alvo.

6. Mas, se é racional aceitar o Princípio do Fechamento, então, se $S$ sabe que $P$, então $S$ sabe que $\mathrm{Q}$, pois pode inferir $\mathrm{Q}$ de $\mathrm{P}$ racionalmente, mediante dedução.

7. Mas, se o passo 6 está correto, então 3 não é satisfeito.

8. Se 3 não é satisfeita, então ou deve-se negar o Princípio do Fechamento ou negar que crenças não-hinge possam ser racionalmente sustentadas.

9. Caso se aceite a segunda metade da disjunção em 8 , então não há suporte algum às nossas crenças não-hinges, e Wittgenstein, consequentemente, não pode oferecer uma solução ao ceticismo.

Para Moyal-Sharrock (2014, pp. 13-4), o que incomoda Pritchard e outros epistemólogos é o fato de Wittgenstein ter colocado uma

\footnotetext{
${ }^{19}$ Não nos interessa expor a solução de Pritchard ao desafio por ele lançado, embora o autor pretenda tentar 'resguardar' a posição original de Wittgenstein, visto que, a nosso ver, seus erros de interpretação estão na origem. O que tentaremos mostrar a seguir.
} 
alternativa para o fim do regresso epistêmico em um tipo de certeza que é não-epistêmica, não-proposicional, indubitável, gramatical e promulgada (enacted), é isto que Pritchard considera algo 'misterioso'. A resposta da autora para as objeções sintetizadas em EP é bastante simples. Afirma que não fazemos uma inferência como aquela indicada no passo 6 do Esquema Pritchard, isso é, não inferirmos uma hinge de uma proposição sobre a qual aparentemente temos conhecimento: "Não acreditaríamos que a batalha de Austerlitz tivesse ocorrido em qualquer ano, se não estivéssemos alicerçados sobre a certeza de que o universo tenha surgido há mais do que cinco minutos" (MOYAL-SHARROCH, 2014, p. 14).

O acarretamento, em função disso, seria apenas aparente, apenas 'invisivelmente' suportaria a proposição sobre a batalha de Austerlitz, e não poderia ser 'resultante' dessa: "o assim chamado acarretamento seria na melhor das hipóteses circular” (MOYAL-SHARROCK, 2014, p. 14). Moyal-Sharrock, pois, ao não aceitar o passo 6 do Esquema de Pritchard, consequentemente rejeita o passo 9.

O 'erro' de Pritchard (PE), para Moyal-Sharrock, poderia ser colocado do seguinte modo (onde P1 seria uma proposição como 'Napoleão venceu a batalha de Auterlitz', e Q a hinge 'A Terra tem mais do que cinco minutos'):

(PE): (Regra) - Proposição P1 - Princípio do Fechamento (ou da Transmissibilidade) - 'Proposição' Q (Hinge) Derivada.

O que D. Moyal-Sharrock (MS) observa é o seguinte:

(MS): Regra - Proposição P1 - (formulação da Regra - Q)

Como se vê no esquema (PE), Pritchard desconsidera que a Proposição P1 já tem sua sustentação em uma regra, como Q, por exemplo ('A Terra tem mais do que cinco minutos'), e que a 'derivação', via Princípio do Fechamento ou suas variantes, apenas alcança uma formulação da regra, e não uma 'proposição' propriamente dita, sujeita ao escrutínio da verdade ou falsidade. Para Moyal-Sharrock, é justamente isso que faz das hinges não-proposicionais, como destacamos antes. $\mathrm{O}$ fato de as hinges serem não-proposicionais é o 
que garante que não haja comprometimento algum da 'viabilidade' de princípios epistêmicos, tais como o do Fechamento. Esse princípio funciona para atitudes proposicionais, afirma a autora, e as hinges, por obséquio, são não proposicionais.

Para a ela, o Princípio do Fechamento e suas variantes tratam de conhecimento, visto que tratam de proposições, e as dobradiças não estão no escopo do conhecimento, não são proposições, mas, regras da gramática. Não aceitar a distinção seria, para Moyal-Sharrock, voltar ao ponto de partida na busca por uma solução ao problema do regresso. No entanto, por que não podemos realizar o tipo de inferência prescrita por Pritchard por meio do altamente plausível Princípio do Fechamento? As observações de Moyal-Sharrock não parecem garantir uma resposta satisfatória à questão, e a autora, ao não esclarecer corretamente o ponto, pode ser acusada de sustentar outra espécie de 'mistério' ${ }^{20}$

É possível, contudo, desfazer o imbróglio que a defesa de MoyalSharrock à leitura não-proposicional das dobradiças pode causar: podemos manter, apesar de não se constituírem em razões para nossas outras crenças, que as dobradiças estão presentes como os fundamentos de nossa ação e de nossas pretensões de sustentar conhecimento de proposições empíricas (e, com isso, mantendo que Wittgenstein responde corretamente ao problema do regresso epistêmico). Não é preciso descartar o procedimento que Pritchard utiliza, via o Princípio do Fechamento (e talvez nem de suas variantes mais sofisticadas, como o Princípio da Transmissibilidade), para deduzir o 'conhecimento' de uma 'proposição' derivada. Por um lado, 1) tem-se que mostrar como este princípio, em certos contextos, é insuficiente para derivar tanto uma proposição, quanto o conhecimento dessa proposição. Por outro, e em consequência, 2) que a pretensa 'derivação' de uma 'proposição' de que se teria 'conhecimento' (no caso de Q) nada mais é do que a formulação, via o princípio do fechamento, de uma regra, uma

\footnotetext{
${ }^{20}$ Ou seja, o mistério não está em assegurar a não-proposicionalidade das dobradiças, crítica que geralmente ocorre na fortuna crítica - já que é bastante plausível a argumentação de que partimos de certezas para que outras coisas possam ser genuinamente duvidadas - mas, sim, em não mostrar como, ao tomar como ponto de partida a não-proposicionalidade das hinges, este percurso de fato não afeta princípios da argumentação racional, como o Princípio do Fechamento.
} 
dobradiça (o que Moyal-Sharrock apenas esboça ao sustentar que sua leitura não-proposicional não afeta o Princípio do Fechamento, como Pritchard acusa ${ }^{21}$ ). Nesse contexto, o Princípio do Fechamento teria apenas a função heurística de apontar como, apesar de não se constituírem em 'razão' para sustentar conhecimento de proposições, as hinges de fato funcionam como fundações às nossas crenças (dito de outro modo, 'trazê-las à tona').

Para responder 1 , considere o seguinte procedimento, que gostaríamos de chamar de Teste-Dobradiça (TD). Note-se que este é um teste informal, mas, quando tratamos de uma fundação que realmente sustenta-se em uma prática, o teste também é motivo prático para rejeitar a aplicação do Princípio do Fechamento em determinados contextos:

TD: Dada certa proposição P, da qual aparentemente S (um
sujeito qualquer) tem conhecimento, e considerando i) que $S$
seja capaz de realizar competentemente deduçães, ii) que uma
dada proposição Q possa seguir-se, aparentemente, de $S$, iii)
que $S$ seja capaz de manter seu conhecimento de que P, então
iv) S só poderá garantir seu 'conhecimento' de que Q, sobre a
base de P, com auxílio do Princípio do Fechamento, se Q não
estiver pressuposta no conhecimento de $S$ de que P. Quando
isto ocorrer, isto é, quando Q estiver pressuposta no
conhecimento de $S$ de que P, então a dedução é sem valor, e a
utilização do Princípio do Fechamento apenas torna manifesta
a formulação de uma hinge, e, como tal, indica um
procedimento heurístico (e racional!) de manifestação da
hinge, não garante uma 'proposição', apenas manifesta
(formula) uma 'regra'.

Ora, é evidente que 'A Terra tem mais do que cinco minutos', a regra $\mathrm{Q}$ formulada, é dobradiça para a proposição $\mathrm{P}$, 'Napoleão venceu a batalha de Austerlitz em 1805'. Alguém só pode ter vencido uma batalha qualquer se a Terra existe há mais do que cinco minutos. A razão da circularidade, mencionada por Moyal-Sharrock, pois, pode ser explicada com o recurso de TD por meio de um procedimento que em nada afeta a aplicação do Princípio do Fechamento em muitos outros contextos, mas o restringe em contextos como nesse exemplo: como afirmou a autora, nós não fazemos esse tipo de inferência!

${ }^{21}$ Veja Moyal-Sharrock (2014, p. 14). 
A conclusão do Esquema de Pritchard (a saber, o passo 9 de $\mathrm{EP})$, assim, pode ser refutada acrescentando-se três passos ao raciocínio:

\section{Esquema de Pritchard Reformulado (EPR)}

1. Alguém possui sustentação para saber que $P$, 'Napoleão venceu a batalha de Austerlitz em 1805';

2. Uma hinge (dobradiça) relevante no cenário previsto em 1 seria Q: 'A Terra existe há mais tempo do que cinco minutos';

3. Q não pode ser, como é uma hinge, racionalmente sustentada;

4. Q não pode ser racionalmente sustentada, pois é fundamental (em conjunção com outras hinges, em um cenário local) para a negação de um cenário cético radical;

5. Qualquer pessoa racional (S), razoavelmente reflexiva, é capaz de reconhecer que saber que $\mathrm{P}$ implica na rejeição da hipótese cética-alvo.

6. Mas, se é racional aceitar o Princípio do Fechamento, então, se $S$ sabe que $P$, então $S$ sabe que $\mathrm{Q}$, pois pode inferir $\mathrm{Q}$ de $\mathrm{P}$ racionalmente, mediante dedução.

7. Mas, se o passo 6 está correto, então 3 não é satisfeito.

8. Mas, o passo 6 não se aplica, no caso, mediante o que está garantido por TD.

9. Assim o passo 3 pode ser mantido.

10. Para que o passo 3 possa ser mantido, não é preciso rejeitar o Princípio do Fechamento.

11. Logo, as crenças não-hinge podem ser racionalmente sustentadas mediante um conjunto de 'regras', que se manifestam em ação.

12. E, assim, Wittgenstein consequentemente pode oferecer uma solução ao ceticismo, bem como ao problema do Regresso Epistêmico.

Em relação a resposta à questão 2, que levantamos acima, a saber, que a pretensa 'derivação' de uma 'proposição' de que se teria 'conhecimento' (no caso de Q) nada mais é do que a formulação, via o princípio do fechamento, de uma regra, uma dobradiça, O Princípio do Fechamento, se fosse utilizado em circunstâncias como a indicada em $E P R$, seria apenas mais um recurso (heurístico) para elucidar o papel importante que as hinges desempenham em nossos sistemas de crenças. Cabe a ressalva de que, ao formularmos uma hinge, essa peculiaridade da atividade filosófica, seja ela baseada ou não em procedimentos 
racionais, tal como o uso de um princípio bastante plausível na teoria do conhecimento, não 'transforma' uma regra em proposição, não submete uma regra à genuína característica das proposições: estarem abertas ao crivo de sua verdade ou falsidade ${ }^{22}$.

\section{REFERÊNCIAS}

CHILD, W. Wittgenstein. Porto Alegre: Artmed, 2013. GLOCK, H. J. Dicionário Wittgenstein. Tradução de Helena Martins. Revisão de Luiz Carlos Pereira. Rio de Janeiro: Jorge Zahar Editor, 1998.

MOYAL-SHARROCH, D. Unravelling certainty. In: MOYALSHARROCH, D. \& BRENNER, W. In: Readings of Wittgenstein's On Certainty. Hampshire: Palgrave Macmillan, 2005.

Hampshire: Palgrave Macmillan, 2007. . Understanding Wittgenstein's On Certainty. Wittgenstein today. Talk delivered on the occasion of the International Conference on Wittgenstein and Contemporary Philosophy and the Inaugural Meeting of the Chinese Wittgenstein Society, Beijing Normal University 12-13 October 2013. Forthcoming in Conference Proceedings. Disponível em: http://www.academia.edu/5126735/Wittgenstein Today. . The Animal in Epistemology. Wittgenstein's Enactivist Solution to the Problem of Regress. This paper was read at the 6th Annual BWS Conference at the U. of Edinburgh (June 2014); to be published in Hinge Epistemology: Basic Beliefs after Wittgenstein \& Moore, a special issue of the International Journal for the Study of Skepticism, eds A. Coliva \& D. Moyal-Sharrock (2015). 5.7.14.

22 Isso não implica na infalibilidade das hinges, visto que algumas delas podem, no decorrer do fluxo da vida, serem alteradas. No entanto, isso não significa que, quando uma hinge específica for abandonada ou alterada, todo o 'edifício' das hinges tenha de ser abandonado. Se assim o fosse, inclusive nossas práticas de tentar garantir 'conhecimento' de proposições empíricas ficariam completamente comprometidas (GLOCK, 1998, p. 77). 
Disponível em:

http://www.academia.edu/7563211/The_Animal_in_Epistemology_Wit tgensteins_Enactivist_Solution_to_the_Problem_of_Regress PRITCHARD, D. Wittgenstein and the groundlessness of our believing. Synthese, 189(2), 255-272doi: 10.1007/s11229-011-0057-8, 2012 